\title{
Effect of Grain Size on Corrosion Properties of Low Alloy Steel under $\mathrm{H}_{2} \mathrm{~S} / \mathrm{CO}_{2}$ Environment
}

\author{
Hongwei Wang ${ }^{1, *}$, Chi $\mathrm{Yu}^{2}$ \\ ${ }^{1}$ School of Control Engineering, Northeastern University at Qinhuangdao, Qinhuangdao 066004, \\ China; \\ ${ }^{2}$ School of Resources and Materials, Northeastern University at Qinhuangdao, Qinhuangdao 066004, \\ China \\ *E-mail: wanghw0819@163.com
}

doi: $10.20964 / 2017.05 .15$

Received: 28 November 2016 / Accepted: 27 February 2017 / Published: 12 April 2017

The corrosion properties of low alloy steel immersed in $\mathrm{NaCl}$ solution containing $\mathrm{H}_{2} \mathrm{~S}$ and $\mathrm{CO}_{2}$ are investigated. The study is carried out using electrochemical measuring method. Scanning electron microscopy is used to observe the corrosion surface morphology, and the compositions are analyzed by energy-dispersive spectroscopy. The results show that the low alloy steel with more fine grain shows good corrosion resistance, it has lower corrosion current density and bigger the polarization resistance. The relationship of rolling parameters, grain size, electrochemical parameters and corrosion surface morphology are discussed.

Keywords: low alloy steel; $\mathrm{H}_{2} \mathrm{~S} / \mathrm{CO}_{2}$; electrochemical measurements; grey system theory

\section{$\underline{\text { FULL TEXT }}$}

(C) 2017 The Authors. Published by ESG (www.electrochemsci.org). This article is an open access article distributed under the terms and conditions of the Creative Commons Attribution license (http://creativecommons.org/licenses/by/4.0/). 